\title{
Interdisciplinaridade e pesquisa
}

\author{
Interdisciplinarity and research
}

\author{
Ruth M. Chittó Gauer*
}

\begin{abstract}
Resumo: O artigo trata em um primeiro plano da temática da interdisciplinaridade, tendo como foco de análise as questões vinculadas ao tempo e às novas tecnologias. Em um segundo plano, a questão seria o espaço da interdisciplinaridade na atual organização universitária. Poderíamos pensar que na organização universitária construída no passado caberia uma inovação inédita, descolada da concepção especializada?
\end{abstract}

Palavras-chave: Interdisciplinaridade. Especialização. Tecnologia.

Abstract: The article analyzes in a first step the theme of interdisciplinarity, focusing the issues of time and new technologies. On a second moment, the article analyzes the connections between the interdisciplinary spaces in the current form of organization of the university. Is the contemporary structure of the university, grown up on a specialization basis, able to conduct itself an unprecedented renovation guided by the interdisciplinary cooperation, detached from its traditional specialist premise?

Keywords: Interdisciplinarity. Specialization. Technologies.

\section{Preliminares}

Um dos ecos das tecnologias contemporâneas pode ser antevisto no domínio da complexidade que demanda interpretações que perpassem explicações dadas por um único campo de conhecimento. A pesquisa interdisciplinar ocupa um espaço onde aparece todo um movimento de ideias que não estão vinculadas unicamente à proporcionalidade e à perspectiva, próprias de campos especializados do conhecimento. A pesquisa vinculada

* Doutora em História pela Universidade de Coimbra (Portugal), professora nos PPG de História e de Ciências Criminais da Pucrs em Porto Alegre, RS, Brasil. Pesquisa financiada pelo CNPq <chitto@pucrs.br>

\begin{tabular}{|l|l|l|l|l|l|}
\hline Civitas & Porto Alegre & v. 13 & n. 3 & p. 536-543 & set.-dez. 2013 \\
\hline
\end{tabular}


a uma concepção interdisciplinar deve estar em sintonia com a ideia de uma academia preocupada com questões que ultrapassam a visão da pesquisa especializada. A abertura ao diálogo, a quebra de barreira entre os diversos campos do saber deveria pautar o papel das universidades no mundo atual, o qual, como diz Paul Virilio (1993), vive sob o equilíbrio do ciclista.

Há uma questão fundamental a ser analisada: qual seria o espaço da interdisciplinaridade da atual organização universitária? Poderíamos pensar que na organização universitária construída no passado caberia uma inovação inédita, descolada da concepção especializada? Nesse aspecto a contribuição de Bhabha (1994, p. 304) parece importante. Relendo análises de Jameson, o autor chama a atenção, por exemplo, para "as superfícies simulacrais das instituições em geral e da mídia ou [para aquelas] práticas da indústria cultural que produzem investimentos libidinais de caráter mais narrativo". O desafio, então, estaria em redefinir a relação do passado (continuidade), com um presente disjuntivo: encenando o passado como mito, memória, história, uma temporalidade interativa que reinscreve as "lições do passado" na textualidade do presente.

\section{Interdisciplinaridade muitas perguntas e poucas respostas}

Uma concepção que se dá conta da dimensão planetária dos conflitos atuais poderá fazer frente à complexidade de nosso mundo e ao desafio contemporâneo de autodestruição material e espiritual das sociedades. Essas primeiras palavras dos cientistas Lima de Freitas, Edgar Morin e Basarab Nicolescu, que elaboraram o documento $A$ carta de transdisciplinaridade, adotada no Primeiro Congresso Mundial da Transdisciplinaridade, realizado em Portugal, em novembro 1994, permitem refletir sobre os vários riscos que sofre a sociedade contemporânea. A vida está fortemente ameaçada por uma tecnociência triunfante que obedece apenas à lógica assustadora da eficácia pela eficácia. Para além deste aspecto a expansão do conhecimento levou ao surgimento de várias formas de pesquisa que ampliaram de forma significativa todos os campos do saber. Entre os debates, sobre essas novas formas de pesquisa e produção de conhecimento, que ocuparam lugar de destaque na comunidade científica muitos conceitos foram criados. Os mais difundidos e discutidos foram: interdisciplinaridade e multidisciplinaridade. Mais recentemente o conceito de transdisciplinaridade também se faz presente nessas discussões. Podemos pensá-los como multidimensionais. Levando em conta as concepções do tempo e da história, esses conceitos não excluem a existência de um horizonte trans-histórico.

No caso da abordagem interdisciplinar, esta se vincula principalmente a uma preocupação com a formação de novas tecnologias que afetam a 
organização da linguagem, consideramos que a linguagem é o mais perfeito sistema de processamento de informações. Há boas razões para pensar que o alfabeto também afeta a organização do pensamento. Qualquer tecnologia que interfira na criação de novas linguagens afeta também o comportamento físico, mental e emocional do ser humano. A forma como apreendemos ler, escrever, condiciona as rotinas básicas do processamento da coordenação entre os olhos, e o cérebro, que por outro lado exercerão um efeito de feedback nos outros processos psicológicos e sensoriais. Esse fato afeta o processo tradicional da civilização, fazendo com que o conhecimento produzido nos nichos das especializações explique apenas o avanço específico que produziu deixando de lado a questão da disseminação na sociedade e a metamorfose que ocorre no tecido social. Frente a essas questões, que representam apenas uma parcela muito pequena da cultura produzida pelas novas tecnologias, pensamos na perspectivas de que novos ângulos de visão aparecem à medida que novas tecnologias são inseridas. Por outro lado, observamos deslocamentos que permitem acreditar no desdobramento das complexidades por conta da inserção dessas tecnologias.

Não resta dúvidas que a linguagem é a base, o veículo da comunicação social, entende-se que tanto a pesquisa como a sua divulgação a utilize. Embora cada campo do saber o faça de forma específica. Para além dessa afirmativa, Renato Janine Ribeiro, no texto No caminho do futuro (2000) refere que em se tratando das humanidades, "somos pouco rigorosos aos olhos dos que formalizam, porque usamos a linguagem natural, mas o somos em demasia -porque tornamos rigorosa essa linguagem- aos olhos dos que comunicam". Em nota de pé de página, o autor, afirma: "qualquer teórico da linguagem sabe, hoje, que a linguagem, mesmo natural, está longe de ser um veículo para uma comunicação transparente". O equívoco de interpretação, apontado pelo autor, sobre a questão da linguagem, é enfatizado no ponto onde as fronteiras, nas ciências humanas e nas humanidades em geral, são mais permeáveis. O mesmo autor segue dizendo: "Assim, penso que a interdisciplinaridade se produz mais fácil e espontaneamente nas humanas do que nas outras áreas, e isso justamente porque o contato entre uma disciplina e outra é facilitado por uma menor formalização, ou não matematização. $\mathrm{O}$ comum recurso à linguagem natural permite maior fluidez na leitura recíproca".

António Damásio (1994, p. 122) assinala que "é frequente dizer-se que o pensamento não é feito apenas de imagens, que é constituído também por palavras e por símbolos abstratos não imagéticos. Ninguém negará certamente que o pensamento inclui palavras e símbolos. Mas o que essa afirmação não dá 
conta é do facto de tanto as palavras como outros símbolos serem baseados em representações topograficamente organizadas e serem, eles próprios, imagens. A narrativa moderna sobre o tempo legitima e instaura noções que ignoram as multitemporalidades e as intertextualidades, enfatizando a percepção de progresso e evolução como escritura contínua, linear e progressiva, o que permite unificar as diversas temporalidades que caracterizam as culturas num discurso unificado, num discurso cientifico único. O tempo da narrativa moderna, nesse sentido, é homogeneizador, coloca na história, todas as sociedades, todas as descobertas científicas, independente das concepções que as mesmas formularam sobre o tempo" (cf. Gauer, 1998, p. 17). Não choca reconhecer, portanto, usando a afirmativa do autor, que também a ideia de uma verdade absolutizada pela ciência moderna, ao pretender conferir uma ordem a um mundo não previamente organizado de acordo com os seus cânones, se formulou narrativamente. Não podia formular-se a não ser narrativamente (cf. Gauer, 2004, p. 10-11).

A expansão do conhecimento na atualidade retrata essa maior fluidez, maior experiência gerando culturas acadêmicas muito particulares. Dois fenômenos parecem ser mais visíveis nesse processo, o da expansão e o do limite. Ambos simultaneamente criam uma nova estética que se faz mais aceleradamente na segunda metade do século 20, e, mais aparente principalmente nos tempos atuais. A expansão subsidia a ideia do limite e, este, implica deslocamentos e transgressões. Estas duas ideias remetem ainda a presença da ideia de poder. Faz-se necessário pensar que o poder também se desloca provocando a sua ambiguidade.

Nos novos deslocamentos podemos observar algumas ações que estão vinculadas à quebra dos parâmetros das disciplinas. Devemos ter presente que o limite dos deslocamentos pode ser pensado como a fuga da totalidade. Visível também se torna, no entanto, a reutilização de vários conhecimentos especializados na expectativa de criar novas linguagens que permitam uma nova narrativa. Inúmeros temas se tornaram motivos de interesse científico, como por exemplo, a violência, que foge ao parâmetro das especialidades para ser mais amplamente compreendida. Muitos autores pensam que uma análise mais ampla de problemas complexos deveria ser vinculado ao parâmetro da problemática à qual corresponde, a uma opção pela figura do limite, vinculado aos especialistas. Nessa opção, o parâmetro não satisfaz, ao optarmos por uma pesquisa temática, inédita, implica ações em contínuos deslocamentos. Seguindo esse raciocínio, não compactuamos da defesa de um novo método para essas pesquisas assim como da defesa de deslocamentos de métodos entre as diferentes áreas do conhecimento. 
Tudo o que é novo é inédito, o que implica em deslocamentos, não em retorno ao modelo. A defesa de um novo método implica, portanto, no retorno ao modelo criado pela ciência moderna. Assim como não seria o transporte por uma via democrática, pois não se opta apenas pelo diálogo, entre especialistas que atuam em diferentes campos do saber onde os métodos conduzem a pesquisa, há que se levar em consideração as vantagens e desvantagens, dos diálogos e das posições, isso implica entender que se trata de relações estas nem sempre ocorrem de forma harmônica. Deve ser o oposto de uma nova doxa, embora todos convivemos com a disciplina, há uma vontade de juntar o que não implica ser universal. Também não podemos ter a pretensão de tratar essa questão como hegemônica por ser ontológica esta é uma visão equivocada pois, não se trata de um funcionamento, este pode ser pensado provisoriamente como um processo. Não existem locais concretos para se pensar a unidade entre vários campos do saber assim como não se pode cair na armadilha de pretender que seja hegemônico. Sendo assim, devemos fugir da alucinação da hegemonia para não cair na armadilha de se tornar um modelo único.

Outro aspecto merece atenção; trata-se do deslocamento para as margens. Há, no entanto, que levar em consideração a velocidade dos deslocamentos, essa velocidade abre o perigo da banalizacão.

Uma das questões mais instigantes sobre esse processo refere-se à questão da tradição científica. Trata-se do papel que ela pode desempenhar na pesquisa e no ensino interdisciplinar. As respostas a essa questão estão em aberto; porém, ela não pode ser pensada como a consciência do passado que já não pode nos auxiliar. Faz-se necessário negar a existência do real, tanto do passado como do presente, que admite essa primeira tese. Outra concepção igualmente imprecisa, seria a de pensar que o passado tenderia a uma espécie de existência honorária. Não podemos pensar que para haver uma maior eficácia da pesquisa e do ensino interdisciplinar, vista aqui como inédita, o passado estaria simplesmente em retirada, ele estaria perdendo a sua eficiência sem perder o ser passado. Essa posição estaria próxima do absurdo considerar que pudesse existir como tal: este é originariamente passado deste presente. Trata-se, portanto, de deslocar o papel do passado frente à velocidade do presente. Nesse aspecto, as questões voltadas para pensar o papel da tradição devem ser revistas, especialmente, nos fenômenos vinculados à velocidade $\mathrm{e}$ ao risco que essa velocidade gera nos deslocamentos, tal como analisado por Virílio. O passado, enquanto tradição, não desempenha papel central.

A interdisciplinaridade nos reporta a muitas dúvidas, entre elas duas são fundamentais: a primeira, seria a de pensar se é possível afirmar que ela se constitui em uma via de renovação das universidades, e a segunda, se ela seria 
um trampolim para se alcançar novas formas de saber. Embora os adversários que se opõem à ideia de um diálogo entre disciplinas científicas denunciem a utopia científica da interdisciplinaridade e proclamem a persistência das disciplinas como modo de organização dos saberes científicos, os ardentes defensores da interdisciplinaridade se esforçam em mostrar como ela contribui para o desenvolvimento das atividades de pesquisa e ensino e como o principal horizonte para a renovação e a modernização da missão da universidade. Por outro lado, não hesitam em afirmar que a interdisciplinaridade é o futuro, uma opção que a universidade não pode deixar de levar em conta. Em nome da organização disciplinar de saberes, a qual a universidade tem amplamente participado, ela deveria, doravante, assumir um papel capital nos esforços de conscientização e de iniciação buscando a execução da interdisciplinaridade. Entretanto, passada a euforia dos primeiros tempos, o discurso sobre interdisciplinaridade amainou e, hoje, não se observa as mesmas convicções.

A situação atual se caracteriza por uma explosão conceitual e uma proliferação de experiências. A conceituação parece uma mistura inteiramente desarticulada: o campo semântico está totalmente deslocado, as definições de todas as espécies se multiplicam, os pontos de vista sobre o estatuto e as funções divergem e, finalmente, os argumentos dominantes revelam diferenças culturais. As experiências tentadas são todas também plurais e diversificadas e, na maior parte dos casos, concluem no fato de que o projeto pouco alcança desviando-se de todos os parâmetros iniciais. O grande período ao longo do qual ficou-se atrelado ao trabalho de definição e de conceituação da interdisciplinaridade e suas aplicações, conduziu ao deslocamento das diferentes práticas antes que a sua consolidação ocorresse. Mas é prematuro querer renunciar à possibilidade de repensar a organização dos saberes e de conceber formas que privilegiem as interações entre os campos científicos. Como afirmado inicialmente, a interdisciplinaridade não tem um estatuto ontológico. Trata-se de renunciar a sua coisificação e discutir a sua possibilidade de existência como tal. Podemos propor a hipótese, ainda que provisória, que ela é, um processo, uma maneira de apreender a realidade ou uma maneira de encará-la. Sendo assim, há que se conduzir a análise no sentido de desenhar um quadro de referências e esclarecer as experiências práticas. Uma melhor formalização do processo permitirá, certamente verificar se o processo poderá ser formalizado por um dispositivo dotado de confiabilidade de avaliação que dará condições de julgar a qualidade das realizações e das pesquisas desenvolvidas.

Um aspecto não pode ser ignorado, a interdisciplinaridade refere-se, ao mesmo tempo, à pesquisa e ao ensino, dois campos de atividade que são 
fortemente tributários das disciplinas. O choque da interdisciplinaridade foi sentido mais fortemente no ensino e, em particular, no ensino universitário. A avaliação das experiências, realizadas nas universidades só se consolidará se estiver embasada em instrumentos técnicos que levem em conta os aspectos acima desenvolvidos e que permitam formar uma opinião sobre a pesquisa e o ensino universitário e seu impacto nas reformas que se fazem necessárias. Os benefícios e obstáculos no desenvolvimento de um processo interdisciplinar se vinculam pela apresentação de uma nova arquitetura organizacional que abrigue um modelo de trabalho para os processos que desenvolvem atividades desvinculadas dos modelos tradicionais.

A prática do ensino na universidade fica fortemente marcada pelas disciplinas e o choque da interdisciplinaridade explica-se pela ausência de uma abertura descolada da tradição para desenvolver eficazmente o ensino e a pesquisa interdisciplinar. Para suprir esta deficiência, faz-se necessário compreender que a elaboração de um dispositivo de avaliação da qualidade do ensino interdisciplinar dispensa os critérios tradicionais.

Uma hipótese consistente para pensar a superação de alguns problemas das deficiências da interdisciplinaridade é a que decorre dos trabalhos de Prigogine (1996). Ao fixar-se nos processos de auto-organização e de ordem passíveis de emergir em sistemas caóticos, o autor é levado à ideia de que o fenômeno da desordem não inibe, antes estimula, os processos organizativos e a própria renovação constante do universo. Assim, aquela reescrita poderia ser pensada como a possibilidade de descrever o caótico e de trabalhar com ele e sobre ele. No fundo, trata-se de reinventar uma reordenação intelectual que permita reescrever a complexidade e não eliminá-la em favor de uma verdade absolutizada. Faz-se imperativo não negar que vivemos hoje num mundo marcado pela inovação.

\section{Referências}

A CARTA de transdisciplinaridade (adotada no Primeiro Congresso Mundial da Transdisciplinaridade, Convento de Arrábida, Portugal, 2-6 novembro 1994) Lima de Freitas, Edgar Morin e Basarab Nicolescu - Comitê de redação.

BHABHA, Homi, K. O local da cultura. Belo Horizonte: Editora da UFMG, 1994.

DAMÁSIO, António. O erro de Descartes: emoção, razão e cérebro humano. Lisboa: Editora Europa-América, 1994.

GAUER, Ruth M. Chittó. Falar em tempo, viver o tempo! In: Ruth M. Chittó Gauer; Mozart Linhares da Silva (Orgs.). Tempo-história. Porto Alegre: Edipucrs, 1998.

GAUER. Ruth M. Chittó. Conhecimento e aceleração (mito, verdade e tempo). In: Ruth M. Chittó Gauer. A qualidade do tempo para além das aparências históricas. Rio de Janeiro: LumenJuris, 2004. 
PRIGOGINI, Ilya. O fim das certezas. São Paulo: Editora da Unesp, 1996.

RIBEIRO, Renato Janine. No caminho do futuro. In: Ciência Humanas, CT Brasil, Ministério de Ciência e Tecnologia, 2000, p. 3-5.

VIRÍLIO, Paul. A inércia polar. Lisboa: Dom Quixote, 1993.

Autora correspondente:

Ruth M. Chittó Gauer

Av. Ipiranga, 6681 - Partenon,

91530-000 Porto Alegre, RS

Recebido em: 27 maio 2013

Aprovado em: 9 out. 2013 